\title{
Efectos del tratamiento periodontal sobre los marcadores de inflamación sistémica en pacientes con riesgo de enfermedad cardiaca coronaria. Estudio piloto
}

\author{
Néstor J López ${ }^{1 a}$, Antonio Q uintero ${ }^{2 a}$, \\ Marcelo Llancaqueo ${ }^{3}$, Lilian Jara ${ }^{4 b}$. \\ Effects of periodontal therapy on \\ markers of systemic inflammation in \\ patients with coronary heart disease risk
}

\begin{abstract}
Background: Studies investigating effects of periodontal treatment (PT) on markers of inflammation in healthy subjects show conflicting results. Few studies have investigated the effects of PT among subjects with coronary heart disease (CHD) risk factors. Aim: To report the results of a pilot prospective study on the effects of periodontal treatment on markers of inflammation among subjects with CHD risk factors. Material and methods: Seventy three patients aged $53 \pm 6$ years $(25 \%$ males) with chronic periodontitis, dyslipidemia and other CHD risk factors were subjected to PT consisting on root planning and oral metronidazol and amoxicillin for 7 days. Periodontal clinical parameters, serum C-reactive protein (CRP), fibrinogen levels and erythrocyte sedimentation rate (ESR) were assessed before and at 6 weeks after PT. Polymorphisms at the IL1A-889 and IL1B+3954 genes were also genotyped. Results: After the treatment period, CRP levels significantly increased from $3.6 \pm 3.7 \mathrm{mg} /$ L to $5.4 \pm 5.7 \mathrm{mg} / \mathrm{L}(\mathrm{p}=0.001)$. No significant changes were observed in fibrinogen levels and ESR. Higher post-treatment CRP levels were significantly associated with the composite polymorphic genotype at the IL1A-889 and IL1B+3954 genes ( $p=0.0001$ ), and extensive periodontitis $(p=0.005)$. Moderate alcohol consumption appeared as a protective factor for CRP elevation ( $p=0.029$ ). Conclusions: The increase of the CRP levels after PT in patients with CVD risk factors appeared associated with IL-1 gene polymorphisms and extensive periodontitis (Rev Méd Chile 2009; 137: 1315-22).
\end{abstract}

(Key words: Chronic periodontitis; Coronary artery disease; Risk factors)

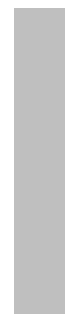
Recibido el 7 de enero, 2009. Aceptado el 1 de septiembre, 2009.
Trabajo financiado por la Universidad de Chile, DI, ENL 05/7 y proyecto FONDECYT \#1061070.
${ }^{1}$ Departamento de Odontología Conservadora, Facultad de Odontología, Universidad de Chile. Santiago, Chile. ${ }^{2}$ Área de Periodoncia e Implantología, Facultad de Odontología, Fa- cultad de Medicina, Universidad de los Andes. ${ }^{3}$ Centro Cardiovascular, Hospital Clínico José Joaquín Aguirre, Facultad de Medicina, Universidad de Chile. ${ }^{4}$ Instituto de Ciencias Biomédicas, Facultad de Medicina, Universidad de Chile.

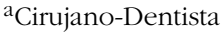
bDoctora en Biología

Correspondencia a: Néstor J. López. José Antonio Soffia

2747, Of. 603, Providencia. Fax: 3345768.

E mail: nlopez@interactiva.cl 
$\mathrm{L}$ a enfermedad periodontal (EP) es un grupo de enfermedades inflamatorias crónicas del periodoncio causadas principalmente por bacterias anaerobias Gram (-) que afecta a $48 \%$ de los mayores de 35 años de Santiago ${ }^{1}$. La infección provoca inflamación crónica que destruye los tejidos de soporte del diente causando su pérdida. La característica clínica-anatomopatológica de la EP es la formación de sacos periodontales alrededor de los dientes. La pared gingival del saco presenta ulceraciones que exponen el tejido conectivo al contenido séptico del saco y la carga bacteriana contra el epitelio ulcerado puede exceder $10^{10}$ de bacterias. Como consecuencia de esto, las bacteremias y endotoxemias son frecuentes durante la masticación o el cepillado de dientes.

En la EP severa la inflamación sostenida es producida por desregulación de la respuesta inmune local con hipersecreción de citoquinas IL-1, IL-6, IL-8 y prostaglandina $\mathrm{E}_{2}^{2}$, y está asociada a polimorfismos genéticos que regulan la respuesta inflamatoria ${ }^{3}$.

Infecciones de baja intensidad, por su respuesta de fase aguda, pueden acelerar la formación de ateromas con el consiguiente aumento del riesgo cardiovascular ${ }^{4}$. La EP está asociada con aumento del riesgo de eventos ateroescleróticos ${ }^{5}$ y la respuesta inflamatoria sistémica (RIS) puede ser un mecanismo de relación entre EP y enfermedad $\mathrm{CV}^{6}$. En la EP hay un aumento moderado de niveles de marcadores de inflamación sistémica (MIS), como proteína C-reactiva (PCR) y fibrinógeno, comparados con sujetos sin $\mathrm{EP}^{7,8}$, por lo que estos marcadores podrían ser factores de asociación entre EP y riesgo $\mathrm{CV}^{8}$.

Los MIS son marcadores de eventos cardiovasculares en sujetos con y sin antecedentes de enfermedad coronaria ${ }^{9}$, y la recurrencia de ellos está asociada con niveles altos de fibrinógeno ${ }^{10} \mathrm{y}$ $\mathrm{PCR}^{11}$, y su aumento es un buen predictor de mortalidad $\mathrm{CV}^{11}$.

El efecto del tratamiento periodontal (TP) en la RIS es controversial ${ }^{12-15}$. Un metaanálisis ${ }^{16}$ no encontró disminución de PCR post-TP y el TP intenso en sujetos sin riesgo CV aumenta la RIS con alteración de la función endotelial y del sistema hemostático $^{17}$. Los efectos del TP en la RIS se han estudiado en sujetos sin riesgo $\mathrm{CV}$, y en sólo un estudio en individuos con riesgo $\mathrm{CV}^{18}$.

La RIS muestra alta variabilidad por patrones individuales de secreción de las citoquinas involu- cradas, asociados con polimorfismos genéticos que regulan la producción de IL-1 ${ }^{19,20}$; y que también están asociados con $\mathrm{EP}^{3}$, infarto agudo del miocardio, accidente isquémico cerebrovascular ${ }^{21,22}$, y con niveles altos de PCR y fibrinógeno ${ }^{23}$.

Investigamos si la eliminación de la EP está asociada con cambios en los MIS en sujetos con riesgo $\mathrm{CV}$, y su relación con polimorfismos de IL1A-899, e IL-1B+3954. La hipótesis propuesta fue que la RIS post-TP en sujetos con riesgo CV es heterogénea y depende de factores que se propone identificar en este estudio piloto para la factibilidad de un posterior estudio aleatorio controlado.

\section{MATERIAL Y MÉTODO}

Medimos los niveles de PCR, fibrinógeno, velocidad de sedimentación (VHS) y parámetros clínicos de EP antes y 6 semanas post-TP para compararlos con estudios similares ${ }^{12-14}$. Seleccionamos estos MIS porque están asociados con riesgo $\mathrm{CV}^{23}$.

Participantes del estudio. Seleccionamos pacientes del programa de prevención de ECV del Consultorio Carol Urzúa de Peñalolén, Santiago, Chile. El programa incluía: examen físico, medición de presión arterial, evaluación nutricional, medición del índice de masa corporal (IMC), análisis de sangre y orina. Según el estado de los pacientes, éstos recibían orientación nutricional, medicación antihipertensiva, hipoglicemiantes y consejería para dejar el tabaquismo.

Criterios de inclusión. Edad $>40$ años, colesterol total $>200 \mathrm{mg} / \mathrm{dL},>14$ dientes presentes y EP. El criterio para diagnosticar EP fue $\geq 4$ dientes con $\geq 1$ sitios con profundidad al sondaje (PS) $\geq 4 \mathrm{~mm} \mathrm{y}$ concomitante pérdida de inserción clínica (PIC) $\geq 3 \mathrm{~mm}$.

Criterios de exclusión. Historia de eventos CV, artritis reumatoidea, historia de $\mathrm{TP}$, terapia de reemplazo hormonal, presencia de otras infecciones intercurrentes, uso de antibióticos, antiinflamatorios no esteroidales o hipolipemiantes en los 6 meses previos al estudio.

Examinamos 120 sujetos y seleccionamos 80, pero sólo 73 aceptaron participar. El protocolo fue 
aprobado por el Comité de Ética de la Facultad de Odontología de la Universidad de Chile, y cada participante firmó un consentimiento informado.

Examen bucal. Un examinador calibrado efectuó exámenes clínicos bucales al inicio del estudio y 6 semanas post-TP. En todos los pacientes se midió: índice de higiene oral por el porcentaje de superficies con placa, PS, PIC y sangrado gingival en 6 sitios por cada diente presente. Estas características miden la severidad, extensión e inflamación gingival de la EP. Se confeccionó una historia médica personal y familiar, y se identificaron y registraron los factores de riesgo $\mathrm{CV}$.

Se diagnosticó hipertensión arterial si la presión sistólica era $\geq 140 \mathrm{~mm} \mathrm{Hg}$ y la diastólica $\geq 90 \mathrm{~mm} \mathrm{Hg}$ en 2 ocasiones, o si recibía terapia antihipertensi$\mathrm{va}^{24}$. Eran fumadores los que habían fumado $\geq 100$ cigarrillos en su vida y aún fumaban, y no fumadores los que jamás lo habían hecho o los que habían fumado $\leq 100$ cigarrillos en su vida, y no fuman en la actualidad ${ }^{25}$. El consumo de alcohol se midió por el número de vasos de vino semanales.

Marcadores de inflamación sistémica. Los niveles de PCR, fibrinógeno y VHS se midieron en sangre extraída entre las 08:00 y 10:00 AM, después de $\geq 8$ horas de ayuno. Antes de tomar las muestras se aplicó un cuestionario para identificar otras patologías que pudieran afectar los niveles de los MIS.

La PCR se midió con la técnica de immunoturbidometría automatizada de alta sensibilidad (Cobas Integra, Roche Diagnostics. Mannheim, Alemania, límite de detección $0,425 \mathrm{mg} / \mathrm{L}$ ). El fibrinógeno se midió por el método de Clauss y la VHS por procedimientos usuales de laboratorio clínico. Los análisis clínicos fueron realizados ciegos en un mismo laboratorio.

Obtención del ADN y genotipificación. El ADN se extrajo de leucocitos de sangre periférica usando soluciones de purificación de ADN (Lyses Buffer and Chomczynski solution, Winkler Ltda, Santiago, Chile). El ADN se amplificó por la reacción en cadena de la polimerasa. La genotipificación para IL1A-889 C>T (SNP Genbank número de acceso rs1800587) y para IL-1B +3954 C>T (SNP GenBank número de acceso rs16944) fue realizada como está descrita ${ }^{3}$. Los productos obtenidos fueron digeridos con TaqI enzima de restricción y analizados en geles de agarosa ${ }^{19}$.
El primer alelo designado para cada polimorfismo es el más común y es denominado "1" (IL1A-889C o IL-1B+3954C), y el menos común es denominado "2" (IL-1A889T o IL-1B+3954T). Para determinar la validez del método, 20 muestras se genotipificaron 2 veces con resultados idénticos.

Tratamiento periodontal. Se aplicó TP estándar que consistió en instrucciones de higiene bucal, destartraje supra y subgingival y raspado radicular, usando instrumentos ultrasónicos y manuales, bajo anestesia local, por cuadrantes de cada maxilar, en cada sesión. El tratamiento demoró 4 a $6 \mathrm{~h}$ dependiendo del número de dientes. A los pacientes se les proveyó de cepillos y dentífrico. Se administraron metronidazol $(250 \mathrm{mg}$ ) y amoxicilina $(500 \mathrm{mg})(\mathrm{M}+\mathrm{A})$ cada $8 \mathrm{~h}$, por 7 días, a los pacientes con diabetes, con EP extensa, o con inflamación gingival severa. No se indicó uso de enjuagatorios bucales.

Estadística. El cálculo de la muestra se basó en estudios en pacientes sin riesgo CV que encontraron variaciones de $\pm 1 \mathrm{mg} / \mathrm{L}$ de PCR, 6 semanas post- $\mathrm{TP}^{12-14}$. Se propuso que el promedio de PCR post-TP variaría $\pm 1,5 \mathrm{mg} / \mathrm{L}$ con desviación estándar $(D E) \pm 0,5$. Calculamos una muestra de 70 sujetos con poder estadístico de $80 \%$ para detectar diferencias entre los promedios de PRC de 1,85 con un valor $p \leq 0,05$.

Los valores de MIS y de características periodontales se expresaron en promedios \pm DE. Los valores de los MIS no tenían distribución normal y se transformaron logarítmicamente para el análisis. Las diferencias de las variables continuas se analizaron con el test $\mathrm{t}$ de Student, $\mathrm{y}$ de las variables categóricas con Chi-cuadrado. Para correlacionar las variables, previo al análisis de regresión lineal, se usó el coeficiente de Pearson. Un valor de $\mathrm{p} \leq 0,05$ se consideró significativo. Para el análisis se usó el programa SAS (versión 8.2, SAS Institute, Cary, NC, USA).

\section{RESULTADOS}

Los 73 participantes completaron el estudio. La Tabla 1 muestra las características de los pacientes. No hubo cambios en el estilo de vida, incluyendo ejercicio físico, tabaco, alcohol, dieta, IMC o en la 
Tabla 1. C aracterísticas clínicas ( $\mathbf{n = 7 3 )}$

\begin{tabular}{|lcc|}
\hline Característica & & \\
\hline Promedio de edad (años) & $53,47 \pm 6,47$ & \\
Colesterol total (mg/dL), & $238 \pm 29$ & $\%$ \\
\hline \multicolumn{2}{l}{$\mathbf{n}$} & 24,65 \\
\hline Hombres & 18 & 19,17 \\
Diabetes mellitus & 14 & 43,83 \\
Obesidad $\left(\mathrm{IMC}>30 \mathrm{~kg} / \mathrm{m}^{2}\right)$ & 32 & 69,86 \\
Hipertensión arterial & 51 & 49,31 \\
Fumadores & 36 & 64,38 \\
Uso de aspirina $(100 \mathrm{mg} /$ ¿día?) & 47 & 28,76 \\
Uso de alcohol $(<30 \mathrm{~g} / \mathrm{semana})$ & 21 & \\
\hline
\end{tabular}

Los valores están expresados en promedio \pm desviación estándar.

medicación. Cuarenta y cuatro por ciento de los pacientes eran obesos (IMC >30), 19\% tenía diabetes tipo 2, 70\% tenía hipertensión arterial y todos recibían antihipertensivos. El 65\% de los diabéticos no tenía control metabólico adecuado (hemoglobina glicosilada $>8 \%$ ), aunque usaban hipoglicemiantes. Los sujetos que consumían alcohol tomaban $<30 \mathrm{~g}$ semanales. La mayoría de los fumadores fumaba $\leq 5$ cigarrillos/día. Cincuenta y un pacientes recibieron $\mathrm{M}+\mathrm{A}$ con el TP.

La frecuencia de heterocigotos u homocigotos para el alelo 2 en IL-1A-889 fue 50,68\%, y para IL$1 \mathrm{~B}+3954$ fue $42,46 \%$. La frecuencia de polimorfismo del genotipo compuesto (al menos un alelo 2) en IL-1A-889 y IL-1B+3954 fue 35,61\%.

Todos los sujetos tenían pobre higiene oral y EP moderada a severa ( $>50 \%$ de sitios con PIC $\geq 3 \mathrm{~mm}$ ). El promedio de sitios con sangrado gingival $(47 \% \pm$ 20,4\%) muestra inflamación generalizada (Tabla 2).

Todas las características periodontales mejoraron significativamente post-TP ( $\mathrm{p}=0,001)$, demostrando que el tratamiento fue efectivo para reducir la inflamación a niveles compatibles con salud periodontal (Tabla 2).

En pacientes con periodontitis generalizada ( $>50 \%$ de sitios con PS $\geq 4 \mathrm{~mm}$ ) los niveles de PCR mostraron correlación positiva con PS $(\mathrm{r}=0,37$, p $=0,001)$, con el porcentaje de sitios con sangrado gingival $(r=0,28, p=0,013)$ y con el porcentaje de los sitios con PS $\geq 4 \mathrm{~mm}(\mathrm{r}=0,40, \mathrm{p}=0,004)$. Antes del TP la mediana de PCR fue $2 \mathrm{mg} / \mathrm{L}$ (rango intercuartil 2 a 4) y post-TP aumentó a $4 \mathrm{mg} / \mathrm{L}$ (rango intercuartil 4 a 7). El promedio de PCR se elevó significativamente de 3,56 $\pm 3,67 \mathrm{mg} / \mathrm{L}$ antes del TP a 5,36 $\pm 5,68 \mathrm{mg} / \mathrm{L}$ post-TP ( $\mathrm{p}=0,001)$. El fibrinógeno y la VHS aumentaron no significativamente (Tabla 2). El porcentaje de pacientes con PCR $\geq 3 \mathrm{mg} / \mathrm{L}$ aumentó de $37 \%$ preTP a 55\% post-TP ( $\mathrm{p}=0,044)$.

El aumento de PCR post-TP estaba asociado a obesidad ( $p=0,008$ ), diabetes ( $p=0,007$ ), periodontitis generalizada $(\mathrm{p}=0,008)$ y polimorfismo compuesto $(\mathrm{p}=0,026)$ (Tabla 3). El aumento del fibrinógeno estaba asociado con periodontitis generalizada ( $\mathrm{p}$ $=0,035)$, diabetes $(p=0,042)$ y obesidad $(p=0,035)$ (Tabla 3). El uso de antibióticos no mostró relación con los MIS. Los pacientes con aumento de PCR tenían mayor frecuencia de polimorfismos de IL-1A889 e IL-1B+3954 (Tabla 4).

El análisis de regresión lineal mostró que el aumento de PCR post-TP estaba significativamente asociado con polimorfismo del genotipo compuesto $(\mathrm{p}=0,001)$ y periodontitis generalizada $(\mathrm{p}=0,005)$. El consumo de alcohol $(\mathrm{p}=0,029)$ fue factor protector para el incremento de PCR (Tabla 5).

\section{DisCUSIÓN}

El objetivo del estudio fue explorar el efecto del TP sobre la RIS e identificar las variables asociadas a ese efecto. Hubo heterogeneidad de la RIS post-TP 
Tabla 2. Características periodontales y marcadores de inflamación sistémica pre y postratamiento periodontal (t-test no pareado)

\begin{tabular}{|lccc|}
\hline & Pretratamiento & Postratamiento & Valor $\mathbf{p}$ \\
\hline No dientes presentes & $18,80 \pm 3,52$ & $18,80 \pm 3,52$ & NS \\
Profundidad al sondaje & $2,98 \pm 0,67$ & $2,17 \pm 0,39$ & 0,001 \\
Pérdida de inserción & $3,61 \pm 1,56$ & $2,98 \pm 1,18$ & 0,001 \\
\% de sitios con: & & & \\
$\quad$ Sangrado gingival & $47 \pm 20,4$ & $20 \pm 9,3$ & 0,001 \\
$\quad$ Profundidad al sondaje $\geq 4 \mathrm{~mm}$ & $27,25 \pm 20,34$ & $6 \pm 8,7$ & 0,001 \\
$\quad$ Pérdida de inserción $\geq 3 \mathrm{~mm}$ & $64,50 \pm 26,74$ & $54,23 \pm 26.2$ & 0,001 \\
$\quad$ Placa dental & $90 \pm 9,5$ & $48 \pm 21,5$ & 0,001 \\
PCR (mg/L) & $3,56 \pm 3,67$ & $5,36 \pm 5,68$ & 0,001 \\
Fibrinógeno (mg/dL) & $350 \pm 89$ & $354 \pm 83$ & 0,55 \\
Velocidad de eritrosedimentación $(\mathrm{mm} / \mathrm{h})$ & $16 \pm 11,28$ & $18,8 \pm 18,29$ & 0,063 \\
\hline
\end{tabular}

Los valores están expresados en promedio \pm desviación estándar.

Tabla 3. Características asociadas a altos niveles de PC $R$ y fibrinógeno post-T P (test-t no pareado)

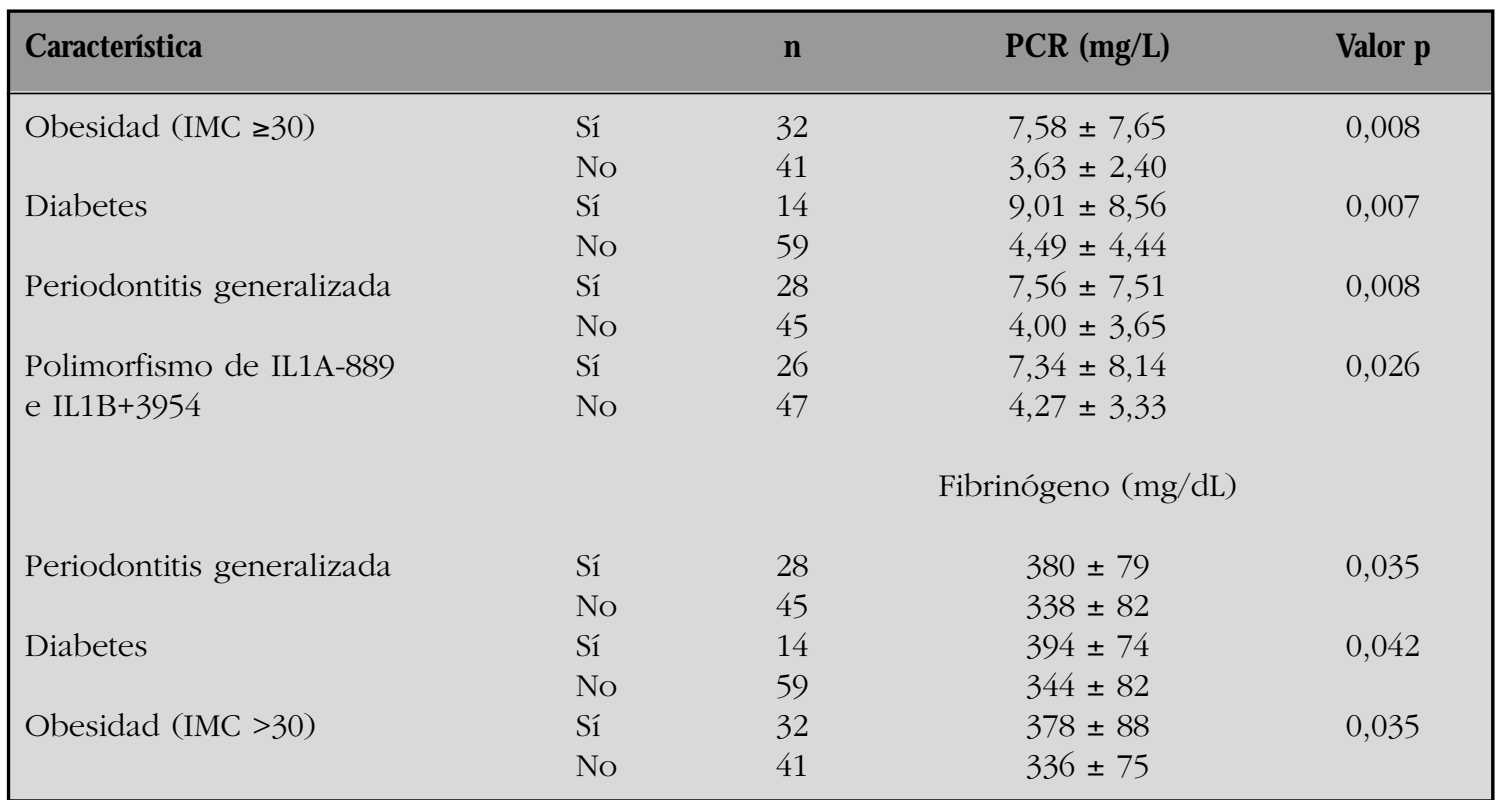

Los valores están expresados en promedio \pm desviación estándar.

medida por los niveles de PCR. El promedio de PCR aumentó significativamente post-TP debido a que en $57 \%$ de los pacientes este marcador aumentó, pero en algunos la PCR se mantuvo y en otros descendió. La mayoría de nuestros pacientes tenía niveles altos de
PCR antes del TP debido a que, además de la EP, tenían hipercolesterolemia y a lo menos otro factor de riesgo $\mathrm{CV}$, como obesidad, diabetes, hipertensión arterial o tabaquismo, todos asociados con aumento de PCR. Valores de PCR $>3 \mathrm{mg} / \mathrm{L}$ indican mayor 
Tabla 4. D istribución de homocigotos y heterocigotos para el alelo 2 en sujetos con aumento y con disminución de niveles de PCR postratamiento (test $\chi^{2}$ )

\begin{tabular}{|c|c|c|c|c|c|}
\hline \multirow[t]{2}{*}{$\begin{array}{l}\text { H omocigoto o } \\
\text { heterocigoto para alelo } 2\end{array}$} & \multicolumn{2}{|c|}{$\begin{array}{c}\text { Aumento de PCR } \\
n=43\end{array}$} & \multicolumn{2}{|c|}{$\begin{array}{c}\text { Disminución de PCR } \\
n=30\end{array}$} & \multirow[t]{2}{*}{ Valor $p$} \\
\hline & $\mathbf{n}$ & $\%$ & $\mathbf{n}$ & $\%$ & \\
\hline IL-1A -899 & 24 & 55,81 & 13 & 43,33 & 0,41 \\
\hline IL-1B +3.954 & 21 & 48,83 & 10 & 33,32 & 0,28 \\
\hline Genotipo compuesto & 19 & 44,18 & 7 & 23,33 & 0,11 \\
\hline
\end{tabular}

Tabla 5. M odelo de regresión lineal para las variables significativamente asociadas a niveles altos de PCR postratamiento periodontal. Variable dependiente: nivel de PCR postratamiento

\begin{tabular}{|lccccc|}
\hline & \multicolumn{2}{c}{$\begin{array}{c}\text { Coeficientes no } \\
\text { estandarizados } \\
\text { Beta }\end{array}$} & $\begin{array}{c}\text { Coeficientes } \\
\text { Error estándar }\end{array}$ & Bdarizados \\
Beta & $\mathbf{t}$ & Valor $\mathbf{p}$ \\
\hline Nivel de PCR postratamiento & 1,037 & 0,106 & 0,679 & 9,814 & 0,0001 \\
Consumo de alcohol & $-2,024$ & 0,906 & $-0,139$ & $-2,235$ & 0,029 \\
Genotipo compuesto & 3,213 & 0,844 & 0,246 & 3,805 & 0,0001 \\
Periodontitis generalizada & 2,467 & 0,854 & 0,196 & 2,888 & 0,005 \\
\hline
\end{tabular}

riesgo de enfermedad coronaria ${ }^{26}$, y mayor riesgo de eventos $\mathrm{CV}^{27,28}$. El 37\% de los pacientes tenía niveles de PCR $>3 \mathrm{mg} / \mathrm{L}$ pre-TP y aumentó significativamente a 55\%, post-TP (p =0,044). Seis semanas post-PT ninguna de las variables asociadas a niveles altos de PCR, con la sola excepción de la EP, se había modificado en nuestros pacientes. Se ha propuesto que la bacteriemia, el daño tisular producido por el TP y la ineficacia para eliminar la infección periodontal, explicarían el aumento de la RIS $^{4,29}$. El TP aplicado en nuestro estudio ha demostrado ser efectivo para eliminar la inflamación periodontal y el metronidazol y amoxicilina son el tratamiento antimicrobiano más efectivo para eliminar infecciones periodontales ${ }^{30}$ y reducir la bacteriemia ${ }^{31}$. La significativa reducción de todas las características clínicas periodontales a niveles compatibles con salud periodontal demuestra que el tratamiento fue efectivo para eliminar la inflamación e infección periodontal.

La administración de antibióticos no mostró asociación con los niveles de PCR, lo que concuerda con otro estudio ${ }^{12}$ en que no hubo disminución de PCR post-TP combinado con metronidazol. Esto sugiere que la bacteriemia no fue un mecanismo importante involucrado en la RIS post-TP en nuestros pacientes. La explicación más probable del aumento de la RIS en algunos pacientes es el trauma tisular derivado del raspado radicular, lo que es congruente con la asociación entre niveles altos de PCR y periodontitis generalizada. Un mayor número de sitios afectados por periodontitis y tratados con raspado radicular involucra mayor extensión de la herida periodontal post-TP.

La heterogeneidad de la RIS al TP se puede explicar por la acción de otros factores individuales, además de la EP. El aumento de PCR post-TP estaba asociado con diabetes y obesidad, la que también estaba asociada con aumento de fibrinógeno y de VHS. Estos resultados son concordantes con que el síndrome metabólico, la resistencia a la insulina y la diabetes, se asocian a niveles altos de MIS $^{32}$.

El tabaquismo está asociado con aumento de $\mathrm{PCR}^{33}$, relación que no estaba en nuestros pacientes, probablemente porque los fumadores fumaban $<5$ cigarrillos diarios. Tampoco hubo relación entre aspirina y PCR en nuestros pacientes porque ingerían 
$100 \mathrm{mg} /$ día, dosis inferior a $300 \mathrm{mg} /$ día, necesaria para reducir la $\mathrm{PCR}^{34}$. El consumo moderado de alcohol fue un factor protector del incremento de PCR lo que concuerda con otros estudios ${ }^{35}$.

Nuestros resultados coinciden con otros en que el TP aumenta la RIS en alta proporción de pacientes $13,15,17,28$, pero están en desacuerdo con Tüter et $\mathrm{al}^{18}$ quienes encontraron disminución significativa de PCR en 36 pacientes con enfermedad coronaria 6 semanas post-TP. Las diferencias entre los dos estudios pueden deberse a que ellos usaron doxiciclina (20 mg por día) que tiene efectos antiinflamatorios, a que no incluyeron diabéticos ni fumadores, y a que sus pacientes tenían colesterolemia normal.

Se ha demostrado que los polimorfismos de IL1A-889 e IL-1B+3954 están asociados con niveles aumentados de IL-19 ${ }^{19}$ y mayor riesgo de EP 3 . La IL-1ß interviene en la regulación de la respuesta inflamatoria sistémica, lo que es congruente con la asociación entre estos polimorfismos y los niveles altos de PCR encontrados en nuestros pacientes. El polimorfismo de IL-1B+3954 aumenta el riesgo de infarto del miocardio y de accidente isquémico cerebral ${ }^{21}$, por lo que nuestros resultados concuerdan con la hipótesis de que ciertos polimorfismos que regulan la secreción de citoquinas proinflamatorias están asociados a mayor riesgo de $\mathrm{ECV}$ y de $\mathrm{EP}^{36}$.

\section{REFERENCIAS}

1. Gamonal Ja, López NJ, Aranda W. Periodontal conditions and treatment needs, by CPITN, in the 35-44 and 65-74 years-old population in Santiago, Chile. Int Dent J 1998; 96-103.

2. Gemmell E, Marshall R, Seymour G. Cytokines and prostaglandins in immune homeostasis and tissue destruction in periodontal disease. Periodontology 2000 1997; 14: 112-43.

3. Kornman KS, Crane A, Wang HY, di Giovine FS, Newman MG, PIRK FW ET aL. The interleukin-1 genotype as a severity factor in adult periodontal disease. J Clin Periodontol 1997; 24: 72-7.

4. Danesh J, Whincup P, Walter M, Lennon L, Thomson A, Appleby P ET AL. LOW grade inflammation and coronary heart disease: prospective study and updated metaanalyses. BMJ 2000; 321: 199-204.

5. Danesh J. Coronary heart disease, Helicobacter pylori, dental disease, Chlamydia pneumoniae, and cytomegalovirus: meta-analyses of prospective studies. Am Heart J 1999; 138: S434-S437.
Hay limitaciones de este estudio que se deben explicitar. Seis semanas es insuficiente para demostrar mejoría de la RIS post-TP, pero se hizo el control a esa fecha para compararlos a estudios de igual duración. No se incluyó un grupo control sin TP por razones éticas, y el tamaño de la muestra es pequeño para determinar asociación genética consistente.

Es aconsejable realizar estudios con mayor número de pacientes y varios polimorfismos genéticos para identificar los factores involucrados en la RIS post-TP en sujetos con riesgo CV.

Para interpretar la RIS se debe tener presente, además de los factores conocidos, que la EP y el TP pueden aumentarla, por lo que se debería incluir un examen bucal para descartar EP, e investigar historia de $\mathrm{TP}$ reciente.

\section{Agradecimientos}

Agradecemos a Unilever Chile por la donación de dentífricos y cepillos dentales para los pacientes, y al Laboratorio Bestpharma Chile por la donación del metronidazol y amoxicilina usados en este estudio.

Las organizaciones que financiaron este estudio no tuvieron injerencia en el diseño del estudio, en la recolección, análisis o interpretación de los datos, revisión o aprobación del manuscrito.

6. D'Aiuto F, Nibali L, Parkar M, Suvan J, Tonetti M. Short-term effects of intensive periodontal treatment and serum inflammatory markers and cholesterol. J Dent Res 2005; 84: 269-73.

7. Slade GD, Offenbacher S, Beck JD, Heiss G, Pankow JS. Acute-phase inflammatory response to periodontal disease in the US population. J Dent Res 2000; 79: 49-57.

8. Wu T, Trevisan M, Genco RJ, Falkner KL, Dorn JP, Sempos CT. Examination of the relation between periodontal health status and cardiovascular risk factors: serum total and high density lipoprotein cholesterol, C-reactive protein, and plasma fibrinogen. Am J Epidemiol 2000; 151: 273-82.

9. Pearson ta, Mensah Ga, Alexander RW, Anderson JL, CANNON RRD, CRIQU M ET AL. Markers of inflammation and cardiovascular disease: application to clinical and public health practice: a statement for healthcare professionals from the Centers for Disease Control and Prevention and the American Heart Association. Circulation 2003; 107: 499-511.

10. Gabay C, Kushner I. Acute-phase proteins and other systemic response to inflammation. N Engl J Med 1999; 340: 448-54. 
11. Mendall MA, Strachan DP, Butland BK, Ballam L, Morris J, Sweetnam PM, Elwood PC. C-reactive protein relation to total mortality, cardiovascular mortality and cardiovascular risk factors in men. Eur Heart J 2000; 21: 1584-90

12. Mattila K, Vesanen M, Valtonen V, Niemine M, Palosuo T, Rasi V, Asikainen S. Effect of treating periodontitis on C-reactive protein levels: a pilot study. BMC Infect Dis 2002; 2 : 30-3.

13. Ide M, McPartlin D, Coward Py, Crook M, Lumb P, WiLSON RF. Effect of treatment of chronic periodontitis on levels of serum markers of acute-phase inflammatory and vascular responses. J Clin Periodontol 2003; 30: 334-40.

14. Yamazaki $\mathrm{K}$, Honda T, Oda T, Ueki-Maruyama $\mathrm{K}$, Nakajima T, Yoshie H, Seymour GJ. Effect of periodontal treatment on the C-reactive protein and proinflammatory cytokine levels in Japanese periodontitis patients. J Periodont Res 2005; 40: 53-8.

15. D'Aiuto F, Ready D, Tonetti MS. Periodontal disease and C-reactive protein-associated cardiovascular risk. J Periodont Res 2004; 39: 236-41.

16. Ioannidou E, Malekzadeh T, Dongari-Bagtzoglou A. Effect of periodontal treatment on serum C-reactive protein levels: a systematic review and meta-analysis. J Periodontol 2006; 77: 1635-42.

17. D'Aiuto F, Parkar M, Tonetti MS. Acute effects of periodontal therapy on bio-markers of vascular health. J Clin Periodontol 2007; 34: 124-9.

18. Tüter G, Kurtis B, Serdar M, Aykan T, Okyay K, Yücel A ET AL. Effects of scaling and root planing and subantimicrobial dose doxycycline on oral and systemic biomarkers of disease in patients with both chronic periodontitis and coronary artery disease. J Clin Periodontol 2007; 34: 673-81.

19. Pociot F, Molvig J, Wogensen L, Worsaae H, Nerup Ja. TAq1 polymorphism in the human interleukin-1 beta (IL-1 beta) gene correlates with IL-1 beta secretion in vitro. Eur J Clin Invest 1992; 22: 396-402.

20. Berger P, McConnell JP, Nunn M, Kornman KS, Sorrell J, Stephenson K, Duff GW. C-reactive protein levels are influenced by common IL-1 gene variations. Citokine 2002; 17: 171-4.

21. Iacoviello L, Di Castelnuovo A, Gattone M, Pezzini A, Assanelli D, Lorenzet R et al. Polymorphisms of the interleukin- $1 ß$ gene affect the risk of myocardial infarction and ischemic stroke at young age and the response of mononuclear cells to stimulation in vitro. Arterioscler Thromb Vasc Biol 2005; 25: 222-7.

22. Eklund C, Jahan F, Pessi T, Lehtimaki T, Hurmme M. Interleukin $1 \mathrm{~B}$ gene polymorphism is associated with baseline C-reactive protein levels in healthy individuals. Eur Cytokine Netw 2003; 14: 168-71.

23. Danesh J, Collins R, Appleby P, Peto R. Association of fibrinogen, C-reactive protein, albumin, or leukocyte count with coronary heart disease: Meta-analyses of prospective studies. JAMA 1998; 279: 1477-82.
24. National High Blood Pressure Education Program. The sixth report of the Joint National Committee on Prevention, Detection, Evaluation and Treatment of High Blood Pressure. Bethesda, MD: National Institute of Health/National Heart, Lung and Blood Institute; 1997. NIH publication $\mathrm{N}^{\mathrm{O}} 98-4080$.

25. Centers for Disease Control and Prevention. Cigarette smoking among adults-United States, 1992, and changes in the definition of current cigarette smoking. MMWR 1994; 43: 342-6.

26. D'Aiuto F, Nibali L, Mohamed-Ali V, Vallance P, TonetTi MS. Periodontal therapy: a novel non-druginduced experimental model to study human inflammation. J Periodont Res 2004; 39: 294-9.

27. D'Aiuto F, Parkar M, Nibali L, Suvan J, Lessem J, TonetTi MS. Periodontal infections cause changes in traditional and novel cardiovascular risk factors: Results from a randomized controlled clinical trial. Am Heart J 2006; 151: 977-84.

28. Blake GJ, Ridker PM. Inflammatory biomarkers and cardiovascular risk prediction. J Intern Med 2002; 252: 283-94.

29. Curb JD, Abbott RD, Rodríguez BL, SAKkinen P, Popper JS, Yano K, Tracy RP. C-reactive protein and the future risk of thromboembolic stroke in healthy men. Circulation 2003; 107: 2016-20.

30. Haffajee AD, Dibart S, Kent RL Jr, Socransky SS. Clinical and microbiological changes associated with the use of 4 adjunctive systemically administered agents in the treatment of periodontal infections. J Clin Periodontol 1995; 22: 618-27.

31. Head TW, Bentley KC, Millar eP, De Vries Ja. A comparative study of the effectiveness of metronidazole and penicillin $\mathrm{V}$ in eliminating anaerobes from postextraction bacteremias. Oral Surg Oral Med Oral Pathol 1984; 58: 152-5.

32. Fröhlich M, Imhof A, Berg G, Hutchinson WL, Pepys MB, BoeIng H ET AL. Association between C-reactive protein and features of the metabolic syndrome, a populationbased study. Diabetes Care 2000; 23: 1835-9.

33. Fröhlich M, Sund M, Lowel H, Imhof A, Hoffmeister A, KoenIG W. Independent association of various smoking characteristics with markers of systemic inflammation in men. Results from a representative sample of the general population (MONICA Augsburg Survey 1994/95) Europ Heart J 2003; 24: 1365-72.

34. Ikonomidis I, Andreltti F, Economou E, Stefanadis $\mathrm{CH}$, Toutouzas P, NihOYANNOPOulos P. Increased pro-inflammatory cytokines in patients with chronic stable angina and their reduction by aspirin. Circulation 1999; 100: 793-8.

35. Imhof A, Froehlich M, Brenner H, Boeing H, Pepys MB, KoENIG W. Effect of alcohol consumption on systemic markers of inflammation. Lancet 2001; 357: 763-7.

36. Kornman KS, Pankow J, Offenbacher S, Beck J, Di Giovine F, Duff GW. Interleukin-1 genotypes and the association between periodontitis and cardiovascular disease. J Periodontol Res 1999; 34: 353-7. 